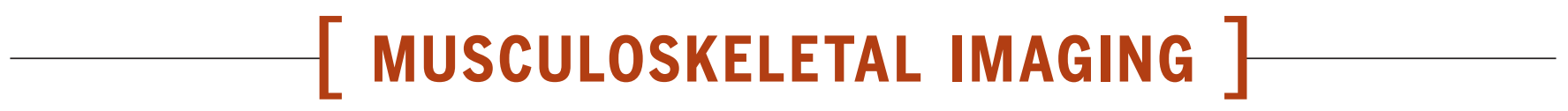

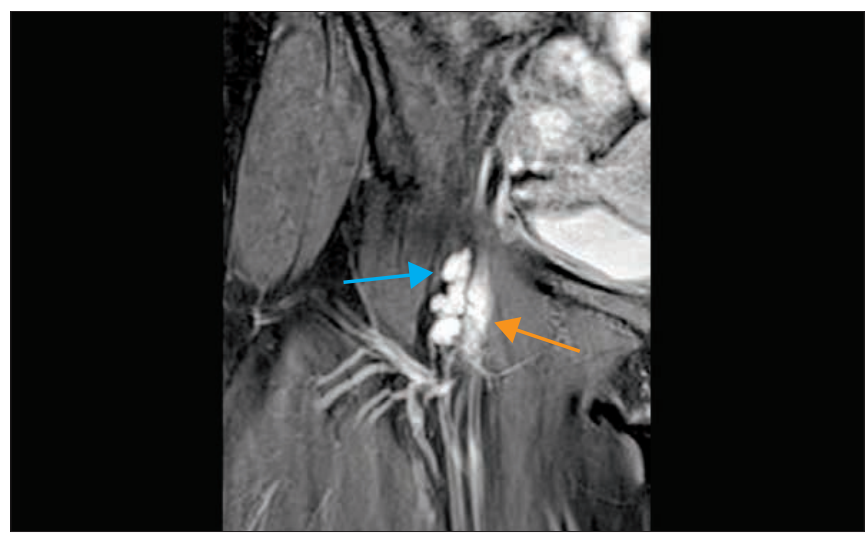

FIGURE 1. Coronal, fat-saturated, proton density-weighted magnetic resonance image shows the multilobulated anterior paralabral cyst (orange arrow) with mass effect on the medial aspect of the femoral nerve (blue arrow).

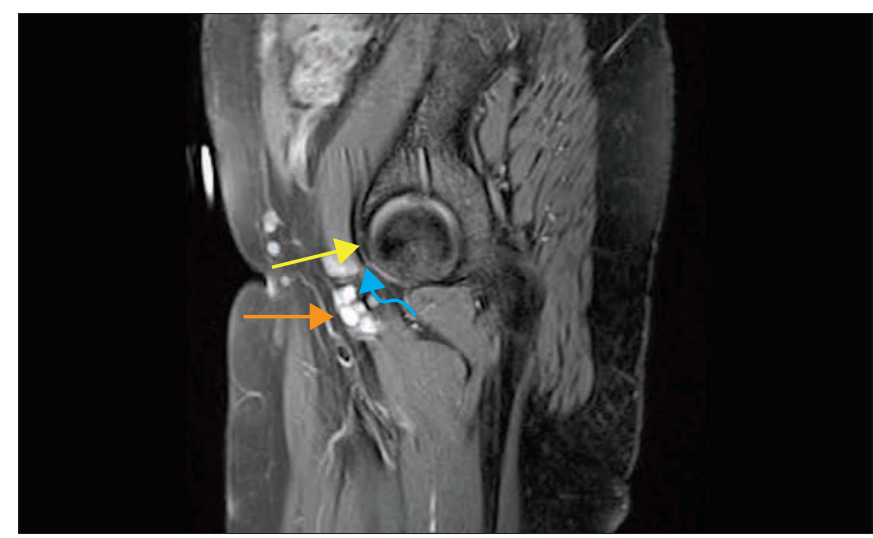

FIGURE 2. Sagittal, fat-saturated, proton density-weighted magnetic resonance image shows an anterior labral tear (yellow arrow) with thin extracapsular extension anteroinferiorly (curved blue arrow), communicating with the multilobulated paralabral cyst (orange arrow).

\title{
Acetabular Paralabral Cyst: An Unusual Cause of Lower Extremity Pain and Paresthesia
}

\author{
MICHAEL P. REIMAN, PT, DPT, OCS, SCS, ATC, FAAOMPT, CSCS, Department of Orthopaedic Surgery, Duke University, Durham, NC. \\ THOMAS W. HASH, 2ND, MD, Department of Radiology, Duke University, Durham, NC. \\ RICHARD C. MATHER, 3RD, MD, Department of Orthopaedic Surgery, Duke University, Durham, NC.
}

5 HE PATIENT WAS A 41-YeAR-OLD woman with an 8-month history of insidious sharp right groin pain and paresthesia radiating distally to the medial lower leg and foot with sitting and any activity involving hip extension. She denied any clicking in her hip. She was previously diagnosed by her internal medicine physician with a femoral hernia. However, surgical correction of hernia, as well as nonsteroidal anti-inflammatory medication, did not alleviate symptoms. Therefore, she was referred for a collaborative consultation with an orthopaedic surgeon and a physical therapist.

Orthopaedic surgeon/physical therapist clinical examination found limited right hip flexion $\left(100^{\circ}\right)$, internal rota- tion $\left(10^{\circ}\right)$, and extension $\left(0^{\circ}\right)$; a positive impingement test $\mathrm{t}^{2,3}$; reproduction of paresthesia along the saphenous nerve distribution of the distal medial thigh, anteromedial knee, and distal medial leg with nerve tension testing ${ }^{1}$; and a negative lumbar spine examination. These were suggestive of potential labral tear, femoroacetabular impingement, and saphenous neuropathy.

Magnetic resonance imaging of the right hip revealed an anterior labral tear with an associated moderate-sized, multilobulated paralabral cyst compressing the medial femoral neurovascular bundle (FIGURES 1 and 2). Mixed cam-pincer femoroacetabular impingement morphology was also present. The patient initially opt- ed for physical therapy. After no relief of symptoms with 6 weeks of physical therapist intervention, the patient opted for surgery over a hip intra-articular injection.

She underwent right hip arthroscopy with acetabular rim trimming, labral repair, and femoral osteochondroplasty. All paresthesia-related symptoms resolved following surgery. However, due to continued hip pain with sitting and resisted hip flexion, the psoas tendon was injected 6 months following arthroscopy, substantially improving her pain. The patient returned to her presymptom functional level after the injection and remained symptom free at her 1-year follow-up. 0 J Orthop Sports Phys Ther 2016;46(1):35. doi:10.2519/jospt.2016.0402

\footnotetext{
References

1. Porchet F, Fankhauser H, de Tribolet N. Extreme lateral lumbar disc herniation: clinical presentation in 178 patients. Acta Neurochir (Wien). 1994;127:203-209. http://dx.doi. org/10.1007/BF01808767

2. Reiman MP, Goode AP, Cook CE, Hölmich P, Thorborg K. Diagnostic accuracy of clinical tests for the diagnosis of hip femoroacetabular impingement/labral tear: a systematic review with meta-analysis. Br J Sports Med. 2015;49:811. http://dx.doi.org/10.1136/bjsports-2014-094302

3. Reiman MP, Goode AP, Hegedus EJ, Cook CE, Wright AA. Diagnostic accuracy of clinical tests of the hip: a systematic review with meta-analysis. Br J Sports Med. 2013;47:893902. http://dx.doi.org/10.1136/bjsports-2012-091035
} 